\title{
Cutaneous Melanoma at an Inner City University Program and the Need for Aggressive Public Awareness Programs: A Pilot, Twelve Year Review
}

\author{
Khurram Tariq ${ }^{1}$, Arezo Farhangi $i^{2} \&$ Fauzia Rana $^{1}$ \\ ${ }^{1}$ Division of Hematology and Medical Oncology, University of Florida College of Medicine, Jacksonville, \\ Florida, USA \\ ${ }^{2}$ School of Medicine, Semnan University of Medical Sciences, Iran \\ Correspondence: Khurram Tariq, MD., Division of Hematology and Medical Oncology, Department of Internal \\ Medicine, University of Florida College of Medicine, 653 West 8th Street, Box L 18, Jacksonville, FL 32209, \\ USA. Tel: 1-919-656-7418. E-mail: Khurram.Tariq@jax.ufl.edu
}

Received: March 18, 2014 Accepted: April 16, 2014 Online Published: May 25, 2014

doi:10.5539/cco.v3n1p30 URL: http://dx.doi.org/10.5539/cco.v3n1p30

\begin{abstract}
Background: Cutaneous melanoma is a very common and lethal subtype of skin cancers. It is associated with certain risk factors, like exposure to UV radiation that can be avoided. It therefore essential to increase public awareness about this malignancy in order to either avoid this cancer altogether or at least be able to diagnose it in its earlier stages.

Method: This is a retrospective review of the Tumor Registry at University of Florida College of Medicine-Jacksonville during the period between the January 1, 1995 and the December 31, 2007. Data was collected on various clinic-pathological variables including the date of registration, age, race, staging and anatomic distribution with special focus on the gender distribution of cutaneous melanoma in our patient population. Anatomic locations were classified into 4 groupings: head and neck, trunk (consisting of the sub regions of the chest, abdomen, groin, upper back, lower back, and buttocks), upper extremities (upper arms, forearms and elbows, and hands), and lower extremities (thighs, lower legs and knees, and feet). Categorical data were analyzed using Chi-square testing.
\end{abstract}

Results: Data analysis from the past 12 years revealed a total of 323 patients with primary cutaneous melanoma with 63\% (205) men, and 37\% (118) females. Median age was 56 years (age range, 14-87 years). Mean age was 55 with SD +/- 16.8, women were younger than men with a mean age at diagnosis of 50 and 57 years respectively $(\mathrm{p}<.05)$. Patients under the age of 35 accounted for $16 \%$ of cases. 317 patients were classified as white (98\%) and 6 were African American (2\%). Mean age was 54 and 58 years for Caucasian and African Americans respectively with $\mathrm{p}=0.035$. Among men, $25 \%$ of the melanomas were on the head and neck, $31 \%$ on the trunk, $23 \%$ on the upper extremities and $12 \%$ on the lower extremities. For women, $17 \%$ of the melanomas were on the head and neck, $29 \%$ on the trunk, $24 \%$ on the upper extremities, and $24 \%$ on the lower extremities. The primary tumor was predominantly located on the trunk in $60 \%$ of the patients, in men (31\%) and in women (29\%) with $\mathrm{P}=0.029$. Significant results are tabulated in the tables listed below.

Conclusion: To our knowledge this is the first study on malignant melanoma from our institution in Jacksonville, Florida. There were more male patients than women, supporting a sex distribution difference of almost 2 to 1 .

Keywords: cutaneous melanoma, public awareness programs, review

\section{Introduction}

Skin cancers in adults are the most common form of cancers in United States and Europe (Adegbidi, Yedomon, Atadokpede, Balley-Pognon, \& do Ango-Padono, 2007). While cutaneous melanomas are less common than Basal and Squamous cell skin cancers, they are by far the most lethal skin cancer and both their incidence and mortality rates have only risen over the past few decades (Desmond \& Soong, 2003; Geller, Swetter \& Brooks, 2007; Pellacani, Scocco \& Vinceti, 2008). While Caucasians have the highest incidence compared to their African American and Hispanic counterparts, recent decades have seen an slow rise in the incidence of 
cutaneous melanomas in minority groups as well (Adegbidi, Yedomon, Atadokpede, Balley-Pognon, \& do Ango-Padono, 2007; Geller, Swetter, \& Brooks, 2007). Besides the variability in melanocytes between subpopulations of different genders, lack of awareness and underreporting might also explain the disparity seen among various minority groups. As with many malignancies, the outcome of melanoma initially depends on the stage at presentation (Balch et al., 2004). Screening and early detection programs ideally detect melanomas at an early and curable stage (Geller, Swetter, \& Brooks, 2007). According to Surveillance, Epidemiology, and End Results (SEER) data, it is the fifth most common cancer among white men and the eighth most common cancer in white females (Ries et al., 2008). The research below is conducted in the backdrop of these grim numbers.

\section{Objective}

In terms of its area, Jacksonville, Florida is the largest city in United States (Cities with 100,000 or More Population, 2004) but to our knowledge, no studies on cutaneous melanomas have ever been carried our area. The purpose of this study is to present a population-based data analysis in Jacksonville with special focus on the incidence of cutaneous melanoma and gender variation in this group of patient population. The intention is to help future melanoma prevention programs.

\section{Methods}

This is a retrospective review of the Tumor Registry at University of Florida College of Medicine-Jacksonville during the period between the January 1, 1995 and the December 31, 2007. Data was collected on various clinic-pathological variables including the date of registration, age, race, staging and anatomic distribution with special focus on the gender distribution of cutaneous melanoma in our patient population. Anatomic locations were classified into 4 groupings: head and neck, trunk (consisting of the sub regions of the chest, abdomen, groin, upper back, lower back, and buttocks), upper extremities (upper arms, forearms and elbows, and hands), and lower extremities (thighs, lower legs and knees, and feet). Categorical data were analyzed using Chi-square testing.

\section{Results}

Data analysis from the past 12 years revealed a total of 323 patients with primary cutaneous melanoma with $63 \%$ (205) men, and 37\% (118) females. Median age was 56 years (age range, 14-87 years). Mean age was 55 with $\mathrm{SD}+/-16.8$, women were younger than men with a mean age at diagnosis of 50 and 57 years respectively (p $<.05)$. Patients under the age of 35 accounted for $16 \%$ of cases. 317 patients were classified as white $(98 \%)$ and 6 were African American (2\%).Mean age was 54 and 58 years for Caucasian and African Americans respectively with $\mathrm{p}=0.035$ as seen in Table 1 . Among men, $25 \%$ of the melanomas were on the head and neck, $31 \%$ on the trunk, $23 \%$ on the upper extremities and $12 \%$ on the lower extremities. For women, $17 \%$ of the melanomas were on the head and neck, $29 \%$ on the trunk, $24 \%$ on the upper extremities, and $24 \%$ on the lower extremities. The primary tumor was predominantly located on the trunk in $60 \%$ of the patients, in men (31\%) and in women (29\%) with $\mathrm{P}=0.029$ as shown in Table 2 .

Table 1. The demographic characteristics of the study population

\begin{tabular}{cccc}
\hline $\begin{array}{c}\text { Age at diagnosis }(\mathrm{y}) \\
\mathrm{N}(\%)\end{array}$ & $\begin{array}{c}\text { Male } \\
\mathrm{N}=204(63.2 \%)\end{array}$ & $\begin{array}{c}\text { Female } \\
\mathrm{N}=119(36.8 \%)\end{array}$ & $\begin{array}{c}\text { Total } \\
\mathrm{N}=323(100 \%)\end{array}$ \\
\hline$<35$ & $24(7.4 \%)$ & $26(8 \%)$ & $50(15.5 \%)$ \\
$35-49$ & $38(11.8 \%)$ & $27(8.4 \%)$ & $65(20.1 \%)$ \\
$50-64$ & $68(21.1 \%)$ & $36(11.1 \%)$ & $104(32.2 \%)$ \\
$>64$ & $74(22.9 \%)$ & $30(9.3 \%)$ & $104(32.2 \%)$ \\
\hline
\end{tabular}

$\mathrm{p}=0.035$ Chi Square significance. 
Table 2. Anatomic distribution of cutaneous melanoma in men and women

\begin{tabular}{cccc}
\hline Regions & $\begin{array}{c}\text { Men } \\
\mathrm{N}=204(\%)\end{array}$ & $\begin{array}{c}\text { Women } \\
\mathrm{N}=119(\%)\end{array}$ & $\begin{array}{c}\text { Total } \\
323(100 \%)\end{array}$ \\
\hline Head and Neck & $51(15.8 \%)$ & $20(6.2 \%)$ & $71(22 \%)$ \\
Trunk & $\mathbf{6 5 ( 2 0 . 1 \% )}$ & $\mathbf{3 3}(\mathbf{1 0 . 2 \% )}$ & $\mathbf{9 8}(\mathbf{3 0 . 3} \%)$ \\
Upper extremities & $45(13.9 \%)$ & $29(9 \%)$ & $74(22.9 \%)$ \\
Lower extremities & $24(7.4 \%)$ & $29(9 \%)$ & $53(16.4 \%)$ \\
Missing & $19(9 \%)$ & $8(7 \%)$ & $27(8.4 \%)$ \\
\hline
\end{tabular}

$\mathrm{p}=0.029$ Chi-Square significance.

Table 3. Staging of cutaneous melanoma in White and African American patients

\begin{tabular}{cccc}
\hline Staging & $\begin{array}{c}\text { White } \\
\text { N=317 (98.1\%) }\end{array}$ & $\begin{array}{c}\text { African American } \\
\mathbf{N = 6}(\mathbf{1 . 9} \%)\end{array}$ & $\begin{array}{c}\text { Total } \\
\mathbf{N}=\mathbf{3 2 3}\end{array}$ \\
\hline Stage 0 & $61(19.2 \%)$ & $0(0 \%)$ & $61(18.9 \%)$ \\
Stage 1 & $94(29.7 \%)$ & $1(16.6 \%)$ & $95(29.4 \%)$ \\
Stage 2 & $25(7.9 \%)$ & $1(16.6 \%)$ & $26(8 \%)$ \\
Stage 3 & $62(19.6 \%)$ & $3(50 \%)$ & $65(20.1 \%)$ \\
Stage 4 & $64(20.2 \%)$ & $1(16.6 \%)$ & $65(20.1 \%)$ \\
Missing & $11(3.4 \%)$ & $0(0 \%)$ & $11(3.4 \%)$ \\
\hline
\end{tabular}

$\mathrm{p}$-value $=0.217$

Table 4.The age at diagnosis in years and staging of cutaneous melanoma

\begin{tabular}{clllllll}
\hline Age at diagnosis & Stage 0 & Stage 1 & Stage 2 & Stage 3 & Stage 4 & Missing & Total \\
\hline$<\mathbf{3 5}$ & $10(3.1 \%)$ & $15(4.6 \%)$ & $5(1.5 \%)$ & $11(3.4 \%)$ & $7(2.2 \%)$ & $2(0.6 \%)$ & $50(15.5 \%)$ \\
$\mathbf{3 5 - 4 9}$ & $11(3.4 \%)$ & $18(5.6 \%)$ & $7(2.2 \%)$ & $14(4.3 \%)$ & $13(4 \%)$ & $2(0.6 \%)$ & $65(20.1 \%)$ \\
$\mathbf{5 0 - 6 4}$ & $19(5.9 \%)$ & $36(11.1 \%)$ & $8(2.5 \%)$ & $16(5 \%)$ & $21(6.5 \%)$ & $4(1.2 \%)$ & $104(32.2 \%)$ \\
$>\mathbf{6 4}$ & $21(6.5 \%)$ & $26(8 \%)$ & $6(1.9 \%)$ & $24(7.4 \%)$ & $24(7.4 \%)$ & $3(0.9 \%)$ & $104(32.2 \%)$ \\
Total & $61(18.9 \%)$ & $95(29.4 \%)$ & $26(8 \%)$ & $65(20.1 \%)$ & $65(20.1 \%)$ & $11(3.4 \%)$ & $312(100 \%)$ \\
\hline
\end{tabular}

p-value $=0.879$.

Table 5. Staging by gender

\begin{tabular}{llllllll}
\hline Gender and Stage & Stage 0 & $\begin{array}{l}\text { Stage 1 } \\
\text { N 95(\%) }\end{array}$ & $\begin{array}{l}\text { Stage 2 } \\
\text { N 26(\%) }\end{array}$ & $\begin{array}{l}\text { Stage 3 } \\
\text { N 65(\%) }\end{array}$ & $\begin{array}{l}\text { Stage 4 } \\
\text { N 65(\%) }\end{array}$ & Missing & Total \\
\hline Men & $39(12.1 \%)$ & $55(17 \%)$ & $15(4.6 \%)$ & $39(12.1 \%)$ & $47(14.6 \%)$ & $9(2.8 \%)$ & $204(63.2 \%)$ \\
Women & $22(6.8 \% \%)$ & $40(12.4 \%)$ & $11(3.4 \%)$ & $26(8 \%)$ & $18(5.6 \%)$ & $2(0.6 \%)$ & $119(36.8 \%)$ \\
Total & $61(18.9 \%)$ & $95(29.4 \%)$ & $26(8.33 \%)$ & $65(20.1 \%)$ & $65(20.83 \%)$ & $11(3.4 \%)$ & $323(100 \%)$ \\
\hline
\end{tabular}

p-value $=0.404$

\section{Discussion}

Our study shows that men have a higher incidence of developing cutaneous melanoma than women and this difference is more evident in older age groups. Men also presented a larger proportion of advanced stage 4 melanomas, however in our study there was no statistically significant different between genders and ageing. These findings are in agreement with other studies showing that men are more likely to die from advanced stage 
melanomas then females (Reyes, Freeman, \& Kuo, 2007). Similar results have been reported in New Zealand where a higher trend toward advanced stage cancers was noted in men (Elwood \& Hislop, 1982). Men, particularly those aged 50 years or older, have a higher incidence and mortality rates associated with melanoma (Field, Lawrence, \& Zwanziger, 2000). Interestingly, in our study women presented at an earlier mean age than their male counterparts and this difference was statistically significant $(\mathrm{p}=0.03)$. This finding may be explained by the fact that in women the incidence of melanomas is highest during the childbearing age and there is a drop around menopause (Schmidt, Nanney, \& Boyd, 2006). The mean age in our female population was 50 years and this may have influenced the lower proportion of melanomas seen in our patient population. Furthermore, we also found an increased proportion of melanomas in males on the head and neck, trunk, back and the upper extremities when compared to women whose rates of distribution tended to stay the same. This is consistent with other studies where cutaneous melanomas where more common on the trunk area in men. Women on the other hand tended have a higher incidence of developing melanomas on their legs (Armstrong \& Kricker, 1994). Various authors have suggested different theories for this disparity ranging from different site-specific sensitivity in melanocytes to the UV radiations to the different pattern of UV exposure based on the hairstyle and the articles of clothing used between the two genders (Elwood \& Gallagher, 1998; Bell, Beyl, \& Schopf, 1992; Bulliard et al., 2000; Green et al., 1992; Bulliard, Cox B, \& Elwood, 1997).

Test for general association between stage and race, shown in Table III was not significant (p-value =.217). There was no significant general association between age group and stage as shown in Table IV (p-value $=.879$ ). Furthermore, the association between gender and stage was also not statistically significant. These findings are shown in Table V (p-value = .404). According to the Surveillance, Epidemiology, and End Results (SEER) data, $81 \%$ of patients with cutaneous melanomas are diagnosed while the cancer is still confined to the primary site (localized stage); $12 \%$ are diagnosed after the cancer has spread to regional lymph nodes or directly beyond the primary site; $4 \%$ are diagnosed after the cancer has already metastasized (distant stage) and for the remaining $4 \%$, the staging information remains unknown (Ries et al., 2008). In our study, the $60 \%$ of the patients had stage $0-2$ disease; $20 \%$ had metastasis to the lymph nodes (Stage 3) and 20\% were diagnosed after the cancer has already metastasized (Stage 4). Hence, forty percent of our patients had advanced cancer at the time of diagnosis. This experience contrasts sharply with SEER data where only $16 \%$ of the patient presented with Stage 3-4.

There are several factors that might explain these findings. Jacksonville is a coastal city and outdoor sports play a very significant part of the lifestyle choices made by this population. Being a part of the "sunshine state", Jacksonville boasts an abundance of sunshine throughout the year. The role of ultraviolet radiations has been well established in the development of cutaneous melanomas (Lee et al., 1984; Gallagher, Elwood, \& Hill, 1986; Kricker et al., 2007; Tuohimaa et al., 2007; Emanuela, Asta, \& Alina, 2010). Persistent exposure to these UV radiations is perhaps one of the most significant factors behind the presence of high stage cutaneous melanomas at the time of diagnosis. This is especially true especially during the summer months when the urge to enjoy the beautiful local beaches is almost irresistible. These observations are in agreement with other studies carried out in the southern United States where both the incidence and mortality. These findings emphasize the need for population wide education drives with focus on avoidance of excessive and unnecessary exposure to sun, use of creams helpful against the harmful solar radiations and protective articles of clothing during all outdoor activities. Progress needs to be made to reach high risk subgroups especially in the low socioeconomic neighborhoods who suffer a disproportionate burden of death from melanoma. Worldwide melanoma control must also be a priority with comprehensive educational and screening programs, especially in communities and hospitals where there are insufficient dermatologists (Geller, Swetter, \& Brooks, 2007). Full-body examinations by primary care physician have been shown to save lives that otherwise would have been lost to melanoma (Geller, Swetter, \& Brooks, 2007). Since most patients typically have contact with their physicians in the year preceding the diagnosis, many lesions can be diagnosed earlier with the assistance of thorough physical examination by the primary care providers especially in the high risk populations (Reyes, Freeman, \& Kuo, 2007; Elwood \& Hislop, 1982). Public awareness programs should educate all segments of the population; however, special focus should be made on patient populations with predilection to the development of cutaneous melanomas. Norway for example, is a European country with the highest incidence of cutaneous melanomas in spite of receiving low intensity UV radiation. Therefore, the higher incidence in Norway is not entirely due to the higher intensity UV radiations but also in part due to host pigmentary characteristics with phenotypes including blue eyes, blond hair and fair skin (Emanuela, Asta, \& Alina, 2010).

Other interesting features to compare besides the risk factors discussed above are the kind of exposure to UV radiations (intermittent vs. continuous UV exposure) and socioeconomic status of our patient population. As we alluded to earlier, Jacksonville is also known as the "sunshine state" and while winters are mild, higher heat indices 
are a norm during the summer months (National Oceanic and Atmospheric Administration, 2014). This makes exposure to the UV radiations a common place and based on these findings the authors would suggest that the exposure type to UV radiations in our city of Jacksonville is continuous. Our patient population generally comprises of the indigenous patients with no healthcare insurance. It will be interesting to follow-up this study with a second retrospective analysis in order to assess the effects of the Affordable Care Act (ACA) or "Obamacare" on this patient population. We recommend a model borrowed after the internally renowned sun protection campaign in Australia during the 1980s "Slip-Slop-Slap." The campaign encouraged the use of protective clothing, use of sun screen and a hat to prevent UV exposure. Even after completion it was extended beyond its initial time span as it was shown to decrease the incidence of cutaneous melanomas in younger populations (Hill, Dobbinson, \& Makin, 2009).

\section{Conclusion}

In conclusion, to our knowledge there has been no previously published data on cutaneous melanomas from Jacksonville, Florida. We found that at our institution, there were more male patients than women, supporting a sex distribution difference of almost 2 to 1 (63\% vs. 37\%). Melanoma cases were overwhelmingly more common in whites than in African Americans. This supports a lower prevalence of melanoma in the black population. Like many retrospective studies of this nature, our study has inherent limitations. The University of Florida College Of Medicine, Jacksonville hospital is an urban hospital in a low socioeconomic region of the country. Our experience may not be reflective of the US as a whole but they can be used to formulate future public health initiates to decrease the incidence and increase awareness about cutaneous melanomas.

\section{References}

Adegbidi, H., Yedomon, H., Atadokpede, F., Balley - Pognon, M. C., \& Ango - Padonou, D. (2007). Skin cancers at the National University Hospital of Cotonou from 1985 to 2004. International journal of dermatology, 46(s1), 26-29. http://dx.doi.org/10.1111/j.1365-4632.2007.03459.x

Armstrong, B. K., \& Kricker, A. (1993). Cutaneous melanoma. Cancer surveys, 19, $219-240$.

Balch, C. M., Soong, S. J., Atkins, M. B., Buzaid, A. C., Cascinelli, N., Coit, D. G., ... \& Thompson, J. F. (2004). An Evidence - based Staging System for Cutaneous Melanoma1. CA: a cancer journal for clinicians, 54(3), 131-149. http://dx.doi.org/10.3322/canjclin.54.3.131

Bell, M., Beyl, C. M., Schopf, R. E., \& Schramm, P. (1992). Light exposure of the lower leg as a pathogenetic factor in the occurrence of malignant melanoma. Dermatology, 185(4), 257-261. http://dx.doi.org/10.1159/000247463

Bulliard, J. L. (2000). Site - specific risk of cutaneous malignant melanoma and pattern of Sun exposure in New Zealand. International Journal of Cancer, 85(5), 627-632. http://dx.doi.org/10.1002/(SICI) 1097-0215(20000301)85:5\%3C627::AID-IJC5\%3E3.0.CO;2-Y

Bulliard, J. L., Cox, B., \& Elwood, J. M. (1997). Comparison of the site distribution of melanoma in New Zealand and Canada. International journal of cancer, 72(2), 231-235. http://dx.doi.org/10.1002/ (SICI)1097-0215(19970717)72:2\%3C231::AID-IJC5\%3E3.0.CO;2-S

Cicarma, E., Juzeniene, A., Porojnicu, A. C., Bruland, Ø. S., \& Moan, J. (2010). Latitude gradient for melanoma incidence by anatomic site and gender in Norway 1966-2007. Journal of Photochemistry and Photobiology B: Biology, 101(2), 174-178. http://dx.doi.org/10.1016/j.jphotobiol.2010.04.002

Data, S. G. (1972). National Oceanic and Atmospheric Administration. Boulder, Colo.

Elwood, J. M., \& Gallagher, R. P. (1998). Body site distribution of cutaneous malignant melanoma in relationship to patterns of sun exposure. International journal of cancer, 78(3), 276-280. http://dx.doi.org/10.1002/(SICI)1097-0215(19981029)78:3\%3C276::AID-IJC2\%3E3.0.CO;2-S

Elwood, J. M., \& Hislop, T. G. (1982). Solar radiation in the etiology of cutaneous malignant melanoma in Caucasians. National Cancer Institute monograph, 62, 167.

Field, M. J., Lawrence, R. L., \& Zwanziger, L. (Eds.). (2000). Extending Medicare coverage for preventive and other services. National Academies Press.

Gallagher, R. P., Elwood, J. M., \& Hill, G. B. (1986). Risk factors for cutaneous malignant melanoma: the Western Canada Melanoma Study (pp. 38-55). Springer Berlin Heidelberg. 
Geller, A. C., Swetter, S. M., Brooks, K., Demierre, M. F., \& Yaroch, A. L. (2007). Screening, early detection, and trends for melanoma: current status (2000-2006) and future directions. Journal of the American Academy of Dermatology, 57(4), 555-572. http://dx.doi.org/10.1016/j.jaad.2007.06.032

Green, A. (1992). A theory of site distribution of melanomas: Queensland, Australia. Cancer Causes \& Control, 3(6), 513-516. http://dx.doi.org/10.1007/BF00052747

Hill, D. J., Dobbinson, S. J., \& Makin, J. K. (2009). Interventions to lower ultraviolet radiation exposure: Education, legislation, and public policy. In American Society of Clinical Oncology (Vol. 2, pp. 526-531).

Holman, C. D., \& Armstrong, B. K. (1984). Cutaneous malignant melanoma and indicators of total accumulated exposure to the sun: an analysis separating histogenic types. $J$ Natl Cancer Inst, 73, 75-82.

Kricker, A., Armstrong, B. K., Goumas, C., Litchfield, M., Begg, C. B., Hummer, A. J., ... \& Berwick, M. (2007). Ambient UV, personal sun exposure and risk of multiple primary melanomas. Cancer Causes \& Control, 18(3), 295-304. http://dx.doi.org/10.1007/s10552-006-0091-x

LEE, J. A. (1982). Melanoma and exposure to sunlight. Epidemiologic reviews, 4(1), 110-136.

Liu, T., \& Soong, S. J. (1996). Epidemiology of malignant melanoma.Surgical Clinics of North America, 76(6), 1205-1222. http://dx.doi.org/10.1016/S0039-6109(05)70511-9

Ortiz, C. A. R., Freeman, J. L., Kuo, Y. F., \& Goodwin, J. S. (2007). The influence of marital status on stage at diagnosis and survival of older persons with melanoma. The Journals of Gerontology Series A: Biological Sciences and Medical Sciences, 62(8), 892-898. http://dx.doi.org/10.1093/gerona/62.8.892

Pellacani, G., Lo Scocco, G., Vinceti, M., Albertini, G., Raccagni, A. A., Baldassari, L., ... \& Seidenari, S. (2008). Melanoma epidemic across the millennium: time trends of cutaneous melanoma in Emilia Romagna (Italy) from 1997 to 2004. Journal of the European Academy of Dermatology and Venereology, 22(2), 213-218.

Ries, L. A. G., Melbert, D., Krapcho, M., Stinchcomb, D. G., Howlader, N., Horner, M. J., ... \& Edwards, B. K. (2008). SEER cancer statistics review, 1975-2005. Bethesda, MD: National Cancer Institute, 1975-2005.

Schmidt, A. N., Nanney, L. B., Boyd, A. S., King, L. E., \& Ellis, D. L. (2006). Oestrogen receptor - $\beta$ expression in melanocytic lesions. Experimental dermatology, 15(12), 971-980. http://dx.doi.org/10.1111/j.1600-0625.2006.00502.x

Statistical Compendia Branch. (2004). Cities with 100,000 or More Population in 2000 ranked by Land Area (square miles)/1, 2000 in Rank Order. U.S. Census Bureau, Administrative and Customer Services Division, March 16, 2004

Tuohimaa, P., Pukkala, E., Scélo, G., Olsen, J. H., Brewster, D. H., Hemminki, K., ... \& Brennan, P. (2007). Does solar exposure, as indicated by the non-melanoma skin cancers, protect from solid cancers: vitamin D as a possible explanation. European Journal of Cancer, 43(11), 1701-1712. http://dx.doi.org/10.1016/j.ejca.2007.04.018

\section{Copyrights}

Copyright for this article is retained by the author(s), with first publication rights granted to the journal.

This is an open-access article distributed under the terms and conditions of the Creative Commons Attribution license (http://creativecommons.org/licenses/by/3.0/). 